\title{
Late development of the categorical perception of speech sounds in pre-adolescent children
}

\author{
Victoria Medina \\ UFR- Linguistique, Université Denis Diderot (Paris 7) France \\ LPE, UMR8581 CNRS \& Université René Descartes (Paris 5) France \\ Willy Serniclaes \\ LPE, UMR8581 CNRS \& Université René Descartes (Paris 5) France
}

While the perilinguistic child is endowed with predispositions for the categorical perception of phonetic features, their adaptation to the native language results from a long evolution from the end of the first year of age up to the adolescence. This evolution entails both a better discrimination between phonological categories, a concomitant reduction of the discrimination between within-category variants, and a higher precision of perceptual boundaries between categories. The first objective of the present study was to assess the relative importance of these modifications by comparing the perceptual performances of a group of 11 children, aged from 8 to 11 years, with those of their mothers. Our second objective was to explore the functional implications of categorical perception by comparing the performances of a group of 8 deaf children, equipped with a cochlear implant, with normal-hearing chronological age controls. The results showed that the categorical boundary was slightly more precise and that categorical perception was consistently larger in adults vs. normal-hearing children. Those among the deaf children who were able to discriminate minimal distinctions between syllables displayed categorical perception performances equivalent to those of normal-hearing controls. In conclusion, the late effect of age on the categorical perception of speech seems to be anchored in a fairly mature phonological system, as evidenced the fairly high precision of categorical boundaries in pre-adolescents. These late developments have functional implications for speech perception in difficult conditions as suggested by the relationship between categorical perception and speech intelligibility in cochlear implant children. 


\section{Introduction}

Categorical perception (CP) is the phenomenon by which differences between stimuli are not perceptible except if they belong to different categories (Liberman, Harris, Hoffman \& Griffith, 1957). The functional interest of CP in speech perception is to filter out irrelevant information for the recognition of lexical units. CP takes part at two levels of speech treatment, a phonetic level and phonological one (Serniclaes, 2000). The CP of phonetic features makes it possible to neutralize acoustic differences in the realization of the same phonetic category in different contexts (for example, the difference in the acoustic salience of the burst vs. formant transitions in $/ \mathrm{ki} / \mathrm{vs}$. $/ \mathrm{ka} /$ ). The CP of phonological features allows to neutralize phonetic differences in the realization of the same phonological category in different contexts (for example, the difference between velar vs. palatal place of articulation in $/ \mathrm{ku} / \mathrm{vs}$. in $/ \mathrm{ki} /$ ).

The perception of phonetic features is largely innate. Prelinguistic children are able to perceive all the phonetic contrasts of the world's languages, even those which do not exist in their linguistic environment (for a review: Vihman, 1996). Categorical perception was first found for a voicing continuum in babies between 1 month and 4 months of age (Eimas, Siqueland, Jusczyk \& Vigorito, 1971), the children reacting to a $20 \mathrm{~ms}$ VOT difference when accompanied by a phonetic difference (a change from /ba/ to /pa/). However, the children hardly did react to the same acoustic difference when it was not accompanied by a phonetic difference.

The linguistic environment has a crucial influence on categorical perception development. Categorical perception changes in the first year of life and adapts itself to the phonemic oppositions of native language (Werker \& Tees, 1984a; Werker \& Logan, 1985; Werker, 2003). The native language contrasts become more categorical than foreign ones. Other discrimination data show that categorical perception evolves between 2 and 6 years (Burnham, Earnshaw \& Clark, 1991). Finally identification data suggest that categorical performances still evolve between 6 and 12 years (Hazan \& Barret, 2000). However, the performances assessed in identification experiments do not pertain to categorical perception (CP) but on the precision of the categorical boundary or "Boundary Precision" (Serniclaes, submitted).

The progressive evolution of categorical perception from childhood to adolescence probably has beneficial consequences for spoken communication. The increase in $\mathrm{CP}$ makes that within-category differences become less discriminated, thereby preventing non-relevant information to reach the mental lexicon. This should facilitate word recognition, especially under difficult listening conditions. The effect of age on categorical perception should therefore enhance communication. 
The abilities to communicate in deaf children might depend on their $\mathrm{CP}$ performances. The cochlear implant (CI) improves hearing, but communication abilities also depend on different other factors, mainly on deafness duration without implant and implantation age (Miyamoto, Osberger, Todd, Robbins, Stroer, Zimmerman-Phillips \& Carney, 1995). These factors seem to act on the development of the phonological level before implantation, as suggested by the effect of the size of the phonemic repertory before implantation on the rate of development after implantation (Serniclaes, Ligny, Schepers, Renglet, \& Mansbach, 2002). A shorter amount of hearing deprivation has the virtue of preserving phonetic predispositions and their developmental potential. However, the precise link between phonological development and speech communication performances remains unknown. One possibility is that phonological development merely depends on the amount of exposure to speech sounds. This would be the case if the innate potential for categorical perception remained intact during deprivation. However, another possibility is that innate capacities need to be activated during some sensitive period in order to preserve their categorical properties. Hearing deprivation would then affect categorical perception to a degree which depends on the duration of deprivation and on the moment at which it occurs during language development. The question then is whether speech communication performances in deaf children with cochlear implants depend or not on their degree of categorical perception of speech sounds.

The first purpose of the present study was to confirm the effect of age on the development of both categorical perception and boundary precision by comparing identification and discrimination performances in a group of preadolescents, aged from 8 to 11 years, with those of their mothers (experiment 1). Our second purpose was to explore the functional implications of $\mathrm{CP}$ by comparing the performances of a group of 8 deaf children, equipped with a cochlear implant, with normal-hearing chronological age controls (experiment 2).

\section{Experiment 1}

\section{$2.1 \quad$ Method}

\subsubsection{Participants}

Two groups of native French speakers took part to this study. One group included 10 normal-hearing children ( 7 boys and 3 girls) aged from 8 to 11 years (average age: 9.3 years, SD: 0.8 ) and were attending normal schools (classes from the second to the fourth grade). The second group included 10 normal- 
hearing adults who were the mothers of these children. The mothers group was aged from 35 to 50 years (average age: 43.2 years, SD: 5.5). All the participants had a normal audition level, as indicated by an audiometric test.

\subsubsection{Stimuli}

\section{Minimal Pairs of Perception and Speech Production Evaluation Protocol with Standardized Stimuli (PEPS).}

The protocol was a modified version of the "Evaluation Test of Speech Production and Perception" (Test d'Evaluation de la Production et de la Perception de la Parole, TEPPP: Vieu, Mondain, Sillon, Piron \& Uziel, 1999). We used the 2 simplified lists of CV syllables recorded of a French speaker. These lists assessed several features per pair (e.g. labiality and frontness, voicing and nasality) and each list had 3 different pairs (e.g. /fo/-/fa/ or $/ \mathrm{sa} /-/ \mathrm{ka} /$ ) and 3 similar pairs (e.g. /fa/-/fa/ or /sa/-/sa/) for the vowels and the consonants. The vowels were presented in /f/ context and the consonants in /a, u, i/ contexts.

\section{Voicing continuum for the categorical perception test}

$\mathrm{CP}$ tests were based on a /də/-/ta/ voicing continuum, composed of 8 stimuli differing in VOT, from $-70 \mathrm{~ms}$ to $+70 \mathrm{~ms}$, by $20 \mathrm{~ms}$ steps (figure 1). The stimuli were generated by modulated sinewave synthesis using software implemented by R. Carré (CNRS, France). The starting frequencies of F1, F2 and F3 transitions were of 200, 2100 and $3100 \mathrm{~Hz}$, respectively. The end values of the transitions were fixed at 500, 1500 and $2500 \mathrm{~Hz}$ respectively for F1, F2, and F3. The F0 was fixed to $120 \mathrm{~Hz}$, transition duration was $24 \mathrm{~ms}$ and the stable vocalic duration was $180 \mathrm{~ms}$.

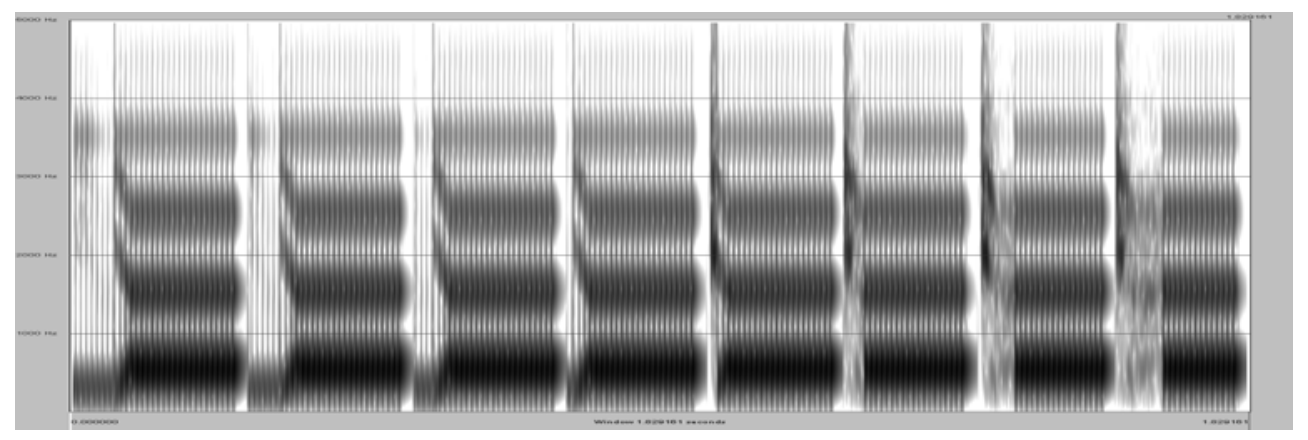

Figure 1: Voicing continuum from $/ \mathrm{d} \partial /$ to $/$ to/. The synthetic stimuli varied along a VOT continuum from -70 to $+70 \mathrm{~ms}$ in $20 \mathrm{~ms}$ steps. 


\subsubsection{Procedure}

The procedure comprised three successive stages: minimal pairs test, discrimination continua endpoints after training, CP tests. The stimuli were delivered through headsets.

The purpose of the training phase was to check correct discrimination of the endpoints of the /do/- /to/ continuum. Participants had to collect at least $75 \%$ correct responses in order to be admitted to the CP test. The latter included 2 tasks, an identification task and a discrimination task, both run with a computer program ("Percep", realized by R. Carré, CNRS). The identification task was run first. Each stimulus was presented 10 times in a pseudo-random order and participants had to identify the stimuli as either /də/ or /ta/. The identification responses were given by pressing one among two different colored keys on the computer keyboard. In the discrimination task, the stimuli were presented by pairs (AX format), comprising either different stimuli (in two different orders: e.g. $-70 \mathrm{~ms}$ VOT followed by $-50 \mathrm{~ms}$ VOT, or $-50 \mathrm{~ms}$ VOT followed by $-70 \mathrm{~ms}$ VOT) or the same stimulus presented twice (e.g. two times $-70 \mathrm{~ms}$ VOT, or two times $-50 \mathrm{~ms}$ VOT). There were 14 different pairs ( 7 stimulus combinations $\mathrm{x} 2$ orders) and 8 same pairs. Each pair was presented 5 times in a pseudo-random order and participants had to respond by answering either "same" or "different". The answers were delivered by pressing either the "M" key for same (i.e. "même" in French) or the "D" key for different on the keyboard. The total procedure took approximately 60 minutes.

Categorical Perception (CP) was assessed by comparing the observed discrimination scores with those expected from the labeling data, the latter being computed with elementary probability formulas (adapted from Pollack \& Pisoni, 1971). The degree of CP is inversely related to the size of the difference between the observed and expected discrimination scores. Boundary precision (BP) tests were based on the slope of the labeling curve, a shallower slope indicating lesser precision. The slope was assessed separately for each participant using Logistic Regression (Mc Cullagh \& Nelder, 1983). Individual assessments of slopes were then used for testing the difference between groups with ANOVA.

\subsection{Results}

Minimal pairs were perfectly discriminated by all participants. The endpoints of the /do/-/ta/ voicing continuum were correctly discriminated with scores above $75 \%$ by all participants. Consequently, we decided to include all the participants in the $\mathrm{CP}$ and $\mathrm{BP}$ assessment tests. 


\subsubsection{Categorical Perception test (/də/- /tə/voicing continuum)}

\section{Identification:}

Examination of the average identification curves of the mothers and children (figure 2) indicates that slope is slightly steeper for the mothers. Comparison between the mean slopes, separately assessed for each participant, showed a significant difference between groups $(\mathrm{F}(1.9)=7.42, \mathrm{p}<0.05)$. The VOT boundary was close to $5 \mathrm{~ms}$ VOT for both groups $(\mathrm{F}<1)$.

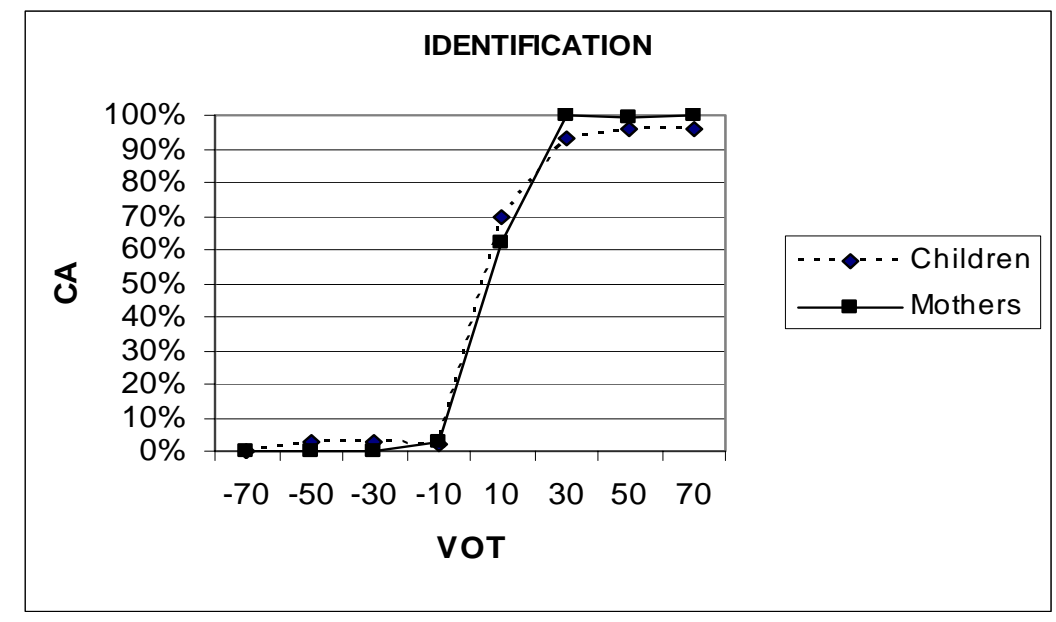

Figure 2: Identification of /də-tə/ continuum for the mothers and children.

\section{Discrimination:}

Figures 3 and 4 show the predicted discrimination and observed discrimination functions for the mothers and children, respectively. The predicted and observed functions were quite similar for the mothers. Discrimination scores were at chance level (50\%), except for the 0 and $20 \mathrm{~ms}$ pairs. These two pairs surround the phonemic boundary (at $5 \mathrm{~ms}$ ). Predicted and observed functions were different for the children. The predicted score was larger than the observed one for the $0 \mathrm{~ms}$ pair while the observed score was larger than the predicted one for the $20 \mathrm{~ms}$ pair. Arcsine transforms of the scores were tested in a repeated measures ANOVA with age (mother vs. child), score type (observed vs. predicted) and VOT as factors. As Mauchly's sphericity test was significant $(\mathrm{p}<.001)$, Greenhouse-Geisser corrected $\mathrm{F}$ values were used. The main effect of VOT was significant $(\mathrm{F}(1.6,14.7)=16.8, \mathrm{p}<.001)$, while those of score type and age were not significant (both $\mathrm{F}<1$ ). The score type $\mathrm{x}$ VOT interaction was marginally significant $(\mathrm{F}(1.6,14.0)=3.58, \mathrm{p}=.065)$, while the age $\mathrm{x}$ score type 
and age $\mathrm{x}$ VOT were not significant (both $\mathrm{F}<1$ ). The age $\mathrm{x}$ score type $\mathrm{X}$ VOT interaction was also marginally significant $(F(1.6,14.7)=3.58, p=.065)$. The examination of contrasts for this latter interaction indicated that when the differences in observed vs. expected discrimination between $0 \mathrm{~ms}$ vs. $20 \mathrm{~ms}$ VOT in the children's results (figure 4) are compared to the absence of such differences in their mothers' results (figure 3), the difference was significant $(\mathrm{F}(1,9)=6.39, \mathrm{p}<.05)$.

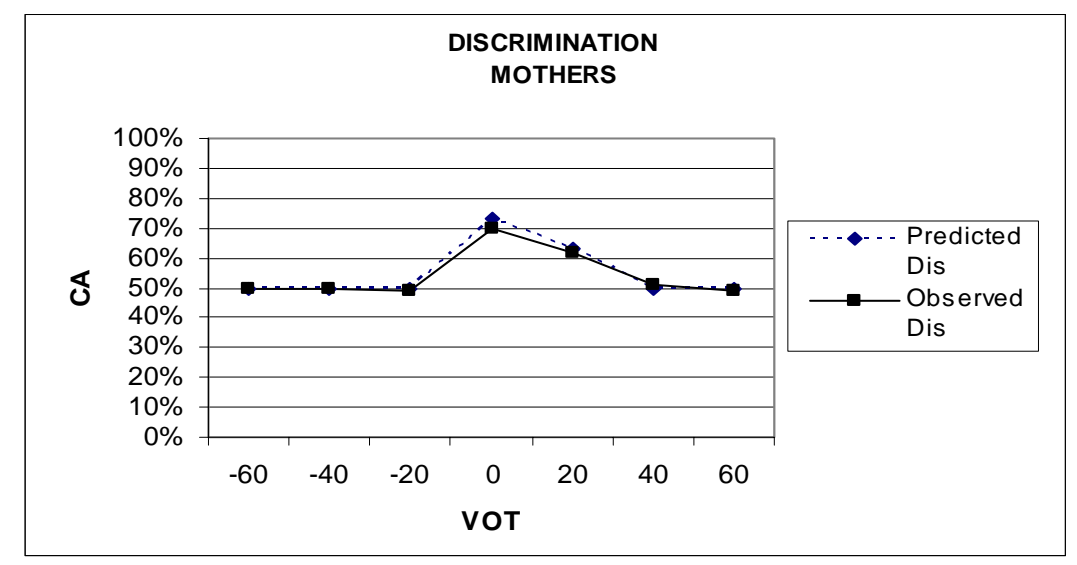

Figure 3: Predicted and observed discrimination of /də-tə/ continuum for mothers group. The VOT represents the average VOT of the stimuli in the pair (for example, -60 corresponds the -70 vs -50 ms VOT pair).

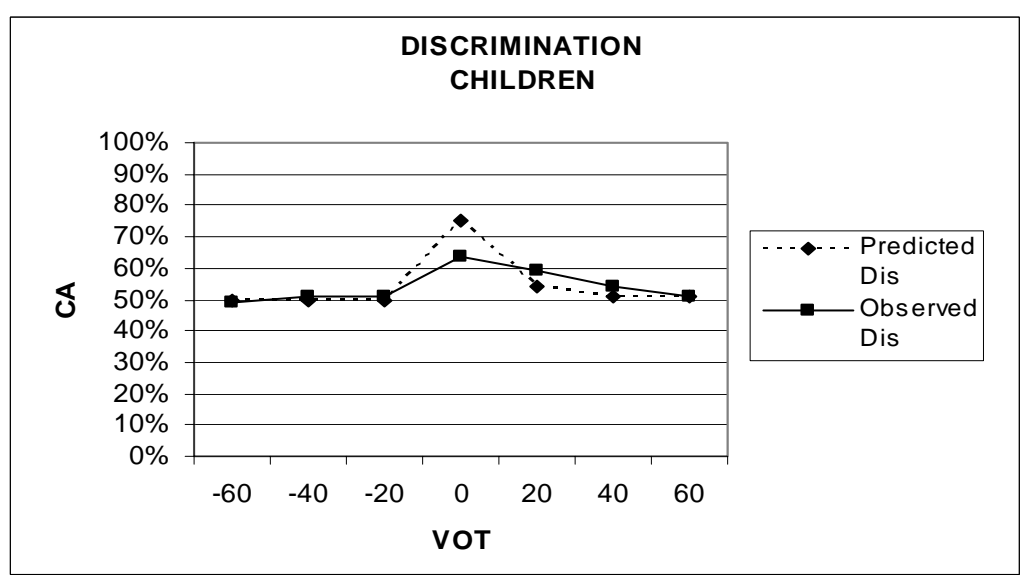

Figure 4: Predicted and observed discrimination of /də-tə/ continuum for children group. 


\subsection{Discussion}

The results of this experiment confirm the effect of age on the precision of the phoneme boundary, previously reported by Hazan and Barret (2000). The results also evidence the presence of a late effect of age on categorical perception. For the adults in this study, observed discrimination scores were closely similar to the expected ones, reflecting almost perfect categorical perception. Children exhibited weaker than expected discrimination for a VOT pair centered on $0 \mathrm{~ms}$ VOT, the stimulus pair closest to the phoneme boundary in this experiment (5 ms VOT). Furthermore, higher than expected discrimination performance was observed for another stimulus pair centered on $20 \mathrm{~ms}$ VOT.

\section{Experiment 2}

\subsection{Method}

\subsubsection{Participants}

Two groups of native French speakers took part to this study. One group of 11 normal-hearing children ( 8 boys and 3 girls) aged from 6 to 11 years (average age: 9 years, SD: 1.3) at a normal school (classes from the second to the fourth grade). This group included the 10 children who already participated in experiment 1 .

The second group included 8 deaf children with cochlear implant (CI), among which 3 were under observation at Trousseau Hospital and 5 were under observation at Robert Debré Hospital, in Paris. These children ( 1 boy and 7 girls) were aged from 5 years 9 months to 11 years (average age: 7.6, SD: 1.6) with a minimum of 3 years of implantation (average duration of implantation use: 4.3, SD: 0.9). We did not use exclusion criteria in relation with either the origin of deafness or the cochlear implant type.

\subsubsection{Stimuli}

Minimal Pairs of Perception and Speech Production Evaluation Protocol with Standardized Stimuli (PEPS)

We used the same simplified minimal pair test as in the experiment 1 . The complete version of the minimal pair test was also used in the present experiment. The test included 2 completed lists which were based on CV syllables of French. The vowels list had 10 different pairs (e.g. /fo/-/fa/) and 10 similar pairs (e.g. $/ \mathrm{fa} / / / \mathrm{fa} /$ ), and it assessed 4 features: aperture, frontness, labiality and nasality. The consonants list included 16 French consonants in /a, 
u, i/ context, 16 different pairs and 16 similar pairs. This list assessed 4 features: manner, place, voicing and nasality.

\section{Voicing continuum from /də/ to /to/ for the categorical perception test}

We used the same voicing continuum from $/ \mathrm{d}$ / / to $/$ ta/ as in the first experiment.

\section{Place continuum for the categorical perception test}

In this experiment we also used a /bo/-/da/ place of articulation continuum, composed of 4 stimuli generated by modification of F2 and F3 transitions (figure 5). The stimuli were generated by modulated sinewave synthesis using software realized by R. Carré (CNRS, France). The F2 and F3 transition onset frequencies varied from $1168 \mathrm{~Hz}$ to $1604 \mathrm{~Hz}$ and from $2330 \mathrm{~Hz}$ to $3211 \mathrm{~Hz}$, respectively. The F1 transition onset was fixed at $200 \mathrm{~Hz}$. The offset transition values were fixed at 500, 1500 and $2500 \mathrm{~Hz}$ for F1, F2 and F3, respectively. A $10 \mathrm{~ms}$ friction noise, with pole frequencies equal to formant onset frequencies, preceded the onset of formant transitions. The F0 was stable at $100 \mathrm{~Hz}$, the durations of negative VOT, formant transitions and vocalic stable segment were of 90,27 and $154 \mathrm{~ms}$, respectively.

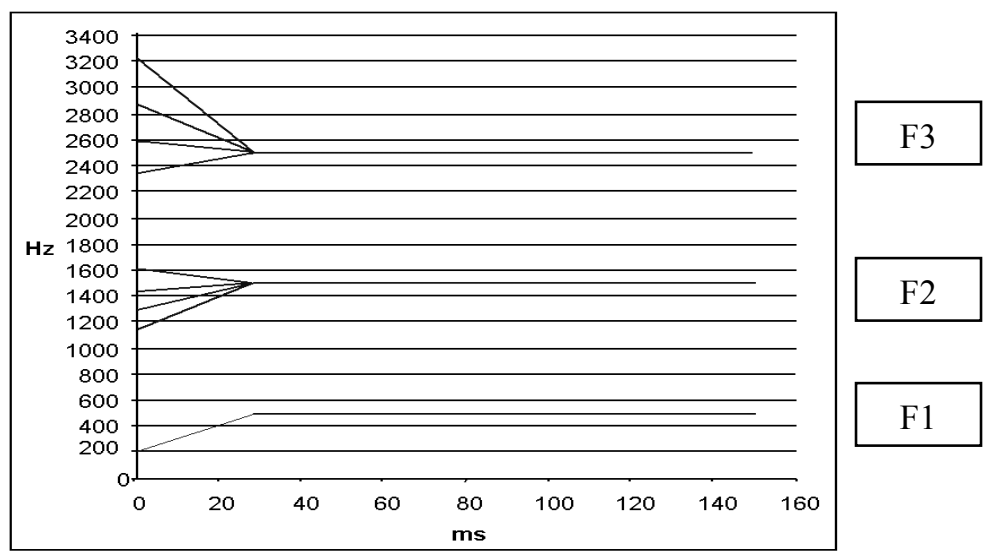

Figure 5: Place continuum from /bə/ to /də/. Stimuli generated by sinewave synthesis, with F2 and F3 modifications.

\subsubsection{Procedure}

The same three-stage procedure as in experiment 1 was used: minimal pairs test, discrimination continua endpoints after training, CP tests. 


\subsection{Results}

All the control children passed the selection stages with 100\% correct responses for the simplified minimal pair discrimination tests and with above $75 \%$ correct discrimination of the endpoints of the /da/-/ta/ voicing continuum.

However, of $8 \mathrm{CI}$ children, 4 did not pass the simplified minimal pair test and 2 did not pass the continuum endpoint discrimination test. These $6 \mathrm{CI}$ children were given the complete minimal pair test. The $2 \mathrm{CI}$ children who passed both preliminary discrimination tests were given the categorical identification and discrimination tests instead.

\section{Minimal Pairs (PEPS)}

Simplified lists. The success average for the control children group was $100 \%$ $\mathrm{CA}$. The average of CI group was $75 \% \mathrm{CA}$. The difference between 2 groups was significant (Mann-Whitney $\mathrm{U}=5.5 ; \mathrm{p}=0.01$ ).
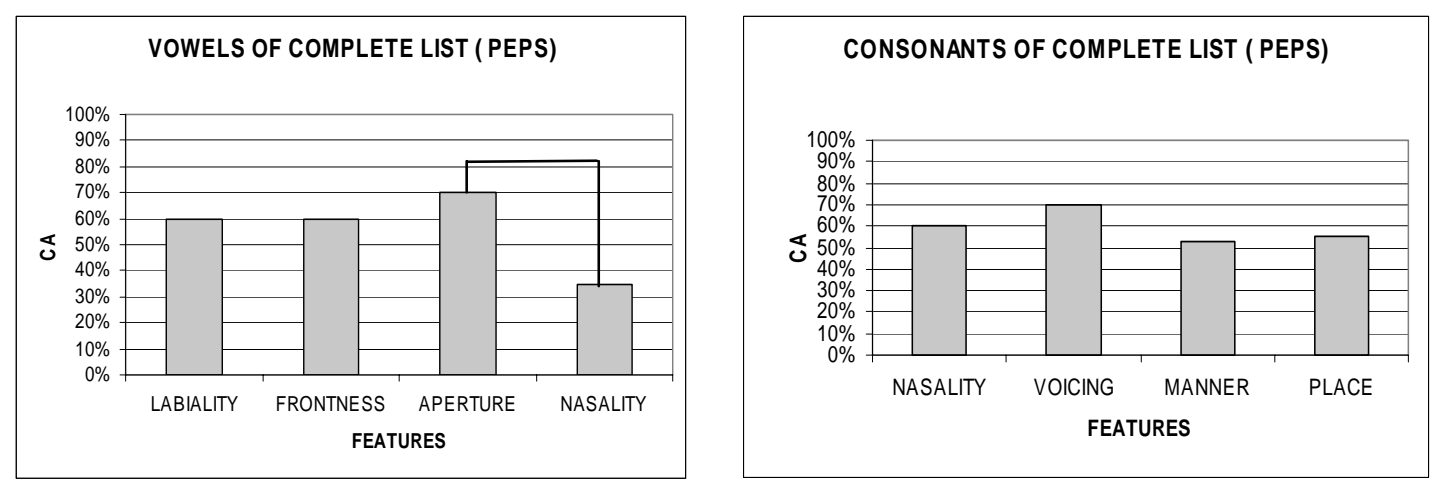

Figure 6: Vocalic features (on the left) and consonant features (on the right) of the complete minimal pairs test (PEPS).

Complete Lists. Six CI children received the complete lists of the PEPS. For the vowels, aperture collected the highest score with $70 \%$ correct discrimination (figure 6). Vowel labiality and frontness obtained $60 \%$ correct discrimination each. The feature most difficult to discriminate was nasality with only $35 \%$ correct responses. Although discrimination differences between vowel features were not significant $(\mathrm{F}(3,6)=3.12 ; \mathrm{p}=0.10)$, the examination of individual contrasts indicated a significant difference between aperture and nasality ( $F$ $(3,6)=3.12 ; \mathrm{p}<0.05)$. The results for consonants showed that the best discriminated features were voicing and nasality with $70 \%$ and $60 \%$ scores respectively. Manner and place were less well discriminated with scores of 53\% 
and 55\% respectively. However, discrimination differences between consonant features were not significant $(\mathrm{F}<1)$.

$\underline{\text { Voicing continuum - Identification: }}$

Examination of the average identification curves of the control children and the curves of the two who were given the $\mathrm{CP}$ tests (figure 7) indicates that the slope was shallower for the CI children vs. the mean of the controls. The VOT boundary of both CI children was similar to that of the control group (about 5 ms VOT). However, voiceless answers of CI child 1 decreased at longer positive VOTs. Table 1 presents the slopes of the two CI children in regard with the distribution of the controls. The distribution of the slopes in usual logit units was positively skewed, logarithmic transforms were used. As can be seen, the slopes of the two CI children fall inside de distribution of the controls (less than 2 SD differences).

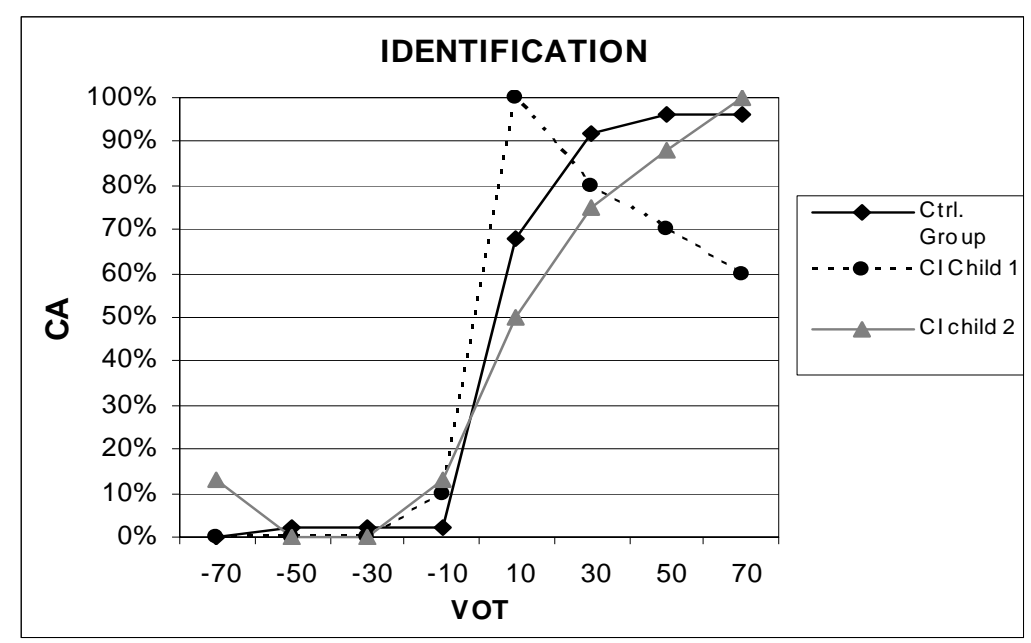

Figure 7: Identification of voicing continuum from /də/ to /ta/ for the control group (11 children) and two CI children.

\section{Voicing continuum - Discrimination:}

Predicted and observed functions along the VOT continuum for the two CI children are presented in figure 8 . The functions of the 11 control children in this experiment were quite similar to those of the subgroup of 10 children already included in experiment 1 for the mother-child comparison (figure 2). CI child 1 presented a drop of observed discrimination instead of an increase around $0 \mathrm{~ms}$. Examination of responses to similar and different pairs revealed that this was due to the conjunction of a bias towards "similar" responding for pairs of stimuli with negative VOT with a bias towards "different" responding 
for pairs of stimuli with positive VOT. CI child 2 presented a better observed discrimination than the predicted discrimination.

Table 1: Slopes of labeling functions for the /də-ta/ voicing continuum.

\begin{tabular}{|c|c|}
\hline & $\begin{array}{l}\text { Slope in } \\
\text { log (logits) }\end{array}$ \\
\hline Control Group Average and SD & $1.01(1.04)$ \\
\hline $\begin{array}{l}\text { CIC } 1 \text { and difference from control's mean } \\
\text { in SD units }\end{array}$ & $-0.24(-1.2)$ \\
\hline $\begin{array}{c}\text { CIC } 2 \text { and difference from control's mean } \\
\text { in SD units }\end{array}$ & $0.11(-0.9)$ \\
\hline
\end{tabular}

Table 2 presents the discrimination results of the two IC children in comparison with the distribution of the controls. Data are summarized in terms of the "Phoneme Boundary Effect" (PBE: Wood, 1976), i.e. the difference in observed discrimination between the across-boundary pair and the mean of within-category pairs. The PBE of Child IC 1 falls outside the distribution of controls, while the one of child IC 2 is inside the distribution.
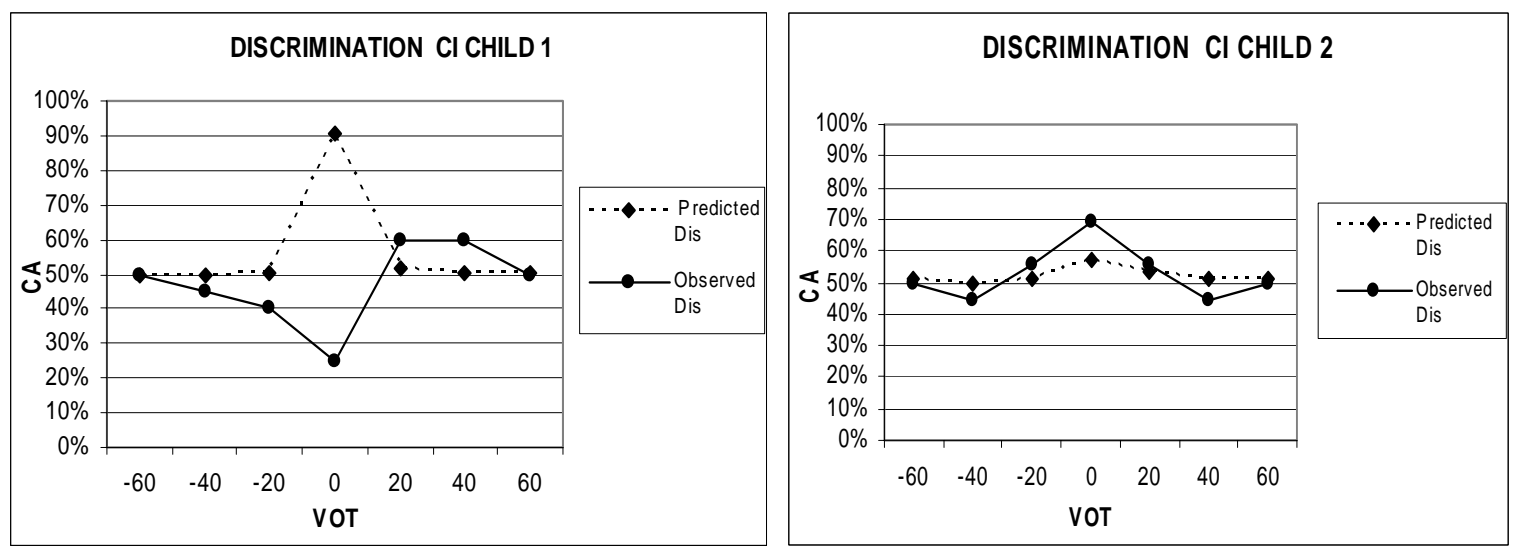

Figure 8: Predicted and observed discrimination on the /də-tə/ continuum for the CI children 1 and 2. 
Table 2: Phoneme Boundary Effect for the /də-tə/ voicing continuum.

\begin{tabular}{|l|c|c|c|}
\hline \multicolumn{1}{|c|}{ Pairs } & PBE & Between-category & Within-category \\
\cline { 1 - 1 } Control Group Average and SD & $17 \%(9.6)$ & $69 \%(10.4)$ & $51 \%(2.6)$ \\
\cline { 1 - 2 } $\begin{array}{l}\text { CIC 1 and difference } \\
\text { from control's mean } \\
\text { in SD units }\end{array}$ & $-7 \%(-2.5)$ & $25 \%(-4.2)$ & $51 \%(0)$ \\
\cline { 1 - 1 } $\begin{array}{l}\text { CIC 2 and difference } \\
\text { from control's mean } \\
\text { in SD units }\end{array}$ & $14 \%(0.3)$ & $69 \%(0)$ & $50 \%(-0.4)$ \\
\hline
\end{tabular}

\section{$\underline{\text { Place continuum - Identification: }}$}

As can be seen in figure 9, the labeling function of CI child 2 is similar to the one of the controls, while the function of CI child 1 is quite irregular and different from the one of the controls. However, the slopes of both CI children fall inside the distribution of the controls (table 3 ).

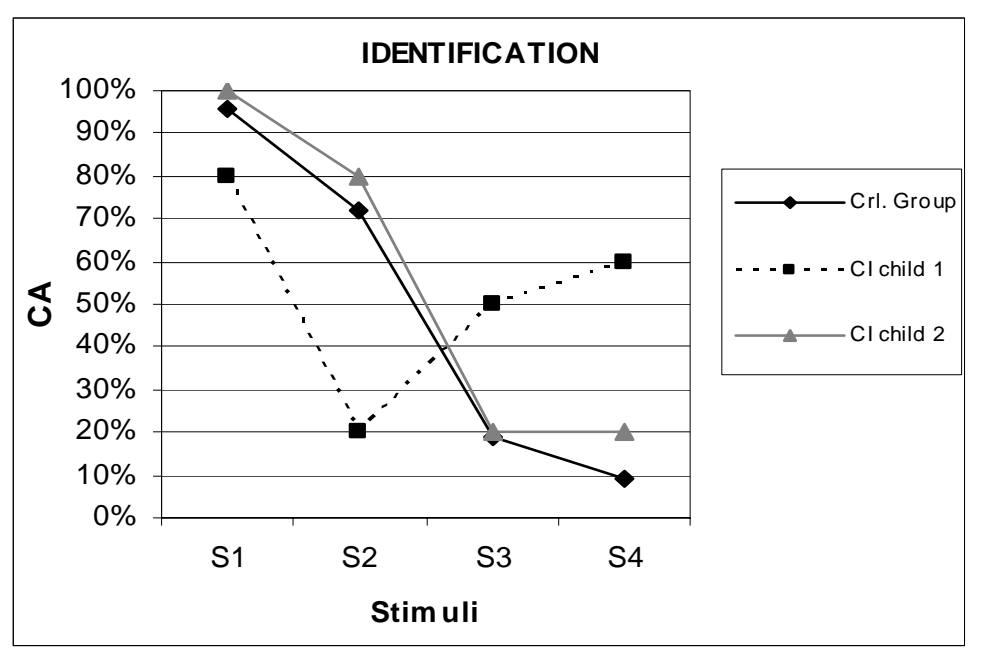

Figure 9: Identification of place continuum from $/ \mathrm{ba/}$ to /da/ for the control group (11 children) and two CI children. 
Table 3: Slopes of labeling functions for the /bə- də/ place continuum.

\begin{tabular}{|c|c|}
\hline & $\begin{array}{l}\text { Slope in } \\
\text { logits }\end{array}$ \\
\hline Control Group Average and SD & $-10.4(9.7)$ \\
\hline $\begin{array}{l}\text { CIC } 1 \text { and difference from control's mean } \\
\text { in SD units }\end{array}$ & $-0.12(-1.1)$ \\
\hline $\begin{array}{l}\text { CIC } 2 \text { and difference from control's mean } \\
\text { in SD units }\end{array}$ & $1.79(-0.9)$ \\
\hline
\end{tabular}

\section{Place continuum - Discrimination:}

For the control group, there was an increase in observed discrimination around the boundary identification (figure 10, pair S2-S3), and the predicted and the observed discrimination functions were fairly similar. The predicted and the observed discrimination functions of CI child 1 were quite different (figure 11). The predicted discrimination varied considerably compared to predicted discrimination of the control group, though the observed discrimination was similar to that of control group. The predicted and observed discrimination functions of CI child 2 were similar. As shown in table 4, for both CI children the PBE was inside the distribution of the controls.

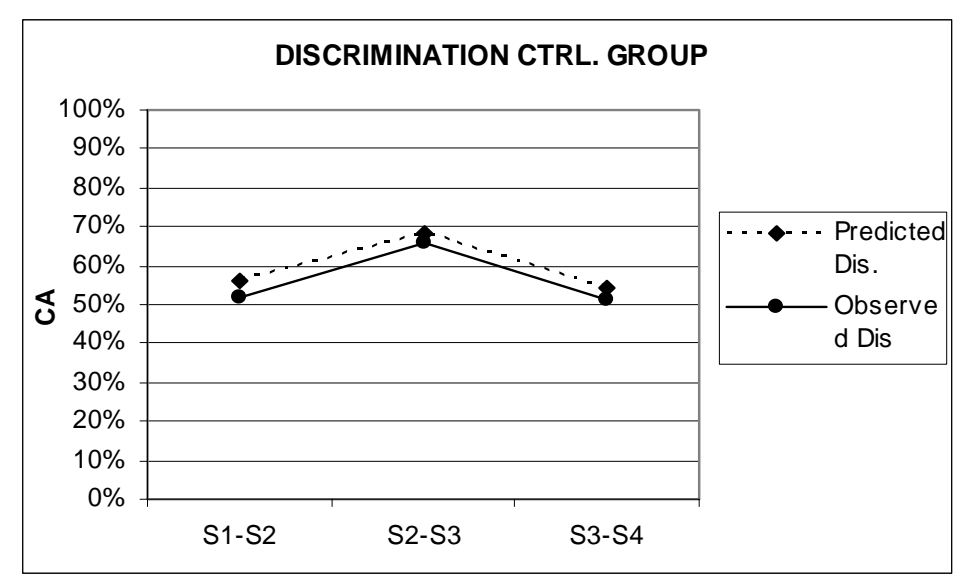

Figure 10: Predicted and observed discrimination of /bədə/ continuum for the control group. 

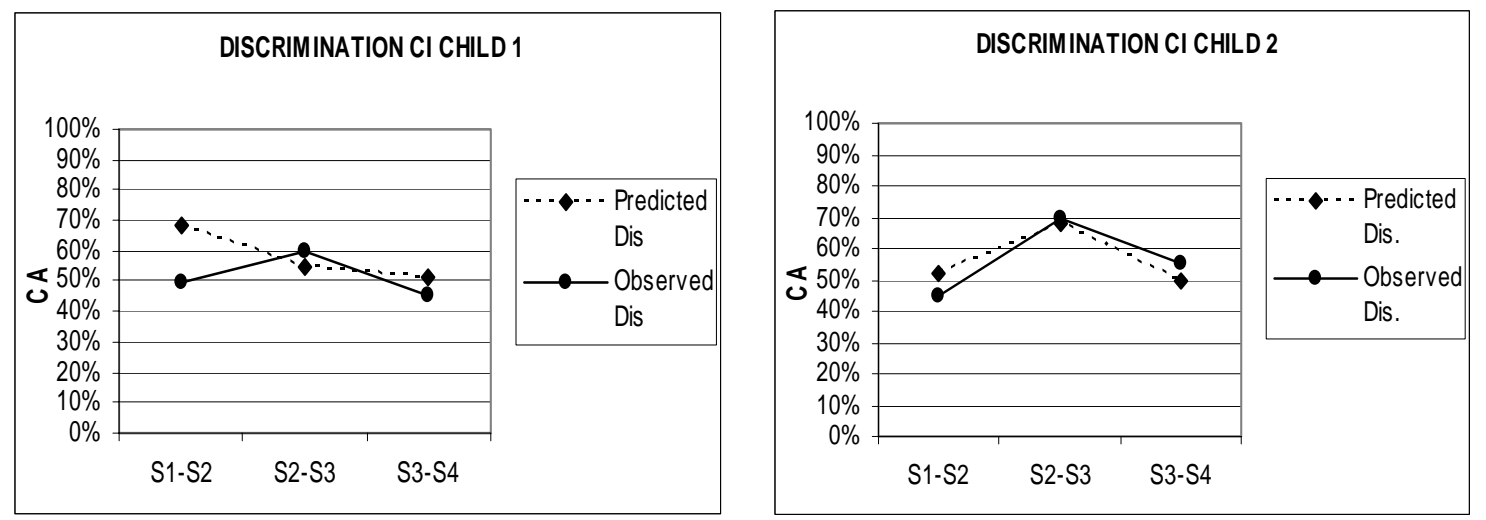

Figure 11: Predicted and observed discrimination of /bədə/ continuum for the CI children 1 and 2 .

Table 4: Phoneme Boundary Effect for the /bo-də/ place continuum.

\begin{tabular}{|l|c|c|c|}
\hline \multicolumn{1}{|c|}{ Pairs } & PBE & $\begin{array}{c}\text { Between- } \\
\text { category }\end{array}$ & Within-category \\
\cline { 1 - 2 } $\begin{array}{l}\text { Control Group Average CA } \\
\text { and SD }\end{array}$ & $17 \%(12.1)$ & $68 \%(12.5)$ & $51 \%(1.7)$ \\
\cline { 1 - 2 } $\begin{array}{l}\text { CA CIC 1 and difference from } \\
\text { control's mean } \\
\text { in SD units }\end{array}$ & $13 \%(-0.3)$ & $60 \%(-0.6)$ & $52 \%(0.6)$ \\
\cline { 1 - 2 } $\begin{array}{l}\text { CA CIC 2 and difference from } \\
\text { control's mean } \\
\text { in SD units }\end{array}$ & $20 \%(0.3)$ & $70 \%(0.2)$ & $57 \%(3.5)$ \\
\hline
\end{tabular}

\subsection{Discussion}

As we have mentioned in an earlier paper (Medina, Loundon, Busquet, Petroff \& Serniclaes, 2004), the CI children in this study have a development of speech perception performances in relation to the duration of cochlear implant use and the chronological age. The 4 children who failed minimal pairs discrimination test had an average of 3.8 years of CI use vs. 4.8 years for the 4 successful children. For the discrimination of the VOT and place continua endpoints, mean durations of CI use were 4.6 years for the 2 children who failed vs. 4.10 years for the 2 successful children. The two children who passed the VOT and place CP tests had almost the same duration of CI use (5.1 years and 4.9 years), although the most categorical one (CI child 2) was 1 year older than the less categorical child (CI child 1). Notice however that there was a significant correlation between chronological age and age of implantation $(\mathrm{r}=0.85$, $\mathrm{p}<0.001)$. 


\subsubsection{Minimal Pairs}

Compared to normal-hearing controls, CI children show difficulties in minimal pair discrimination. For CI children the vocalic feature most difficult to discriminate is nasality and the easiest one is aperture. This does not seem to be specific to the speech perception with CI. The examination of vowel perception by normal-hearing subjects suggests that aperture is more perceptible than other vocalic distinctions (frontness, labiality and nasality; Papçun, 1980). Differences in perceptibility also exist between consonant features, voicing being more solid than other consonant features (Miller and Nicely, 1955). Furthermore, for deaf subjects without CI, voicing is the most robust feature (Vickers et al., 2001) and the same trends appear in the present experiment with CI children, although not in a significant way. To increase statistical power, it would be interesting to continue this study with a greater number of observations by feature.

\subsubsection{Categorical Perception}

The control children are characterized by fairly similar predicted and observed discrimination performance, both for the voicing and place continua used in this experiment. This is also found for one of the two CI children (CI 2) who successfully passed the minimal pair test. The discrimination functions of the other CI child (CI 1) are somewhat different from those of the control group. However, these differences arise from factors not directly related to CP. For the voicing continuum, CI 1 adopted a strategy consisting in answering "similar" to the pairs with negative VOT and to answer "different" those with positive VOT. These two strategies cross near to $0 \mathrm{~ms}$ with a consequence of a fall to correct answers below $50 \%$. This strategy is probably due to the fact that the negative VOT differences are less audible than positive VOT differences for this child. If the child did not perceive the differences between negative VOT stimuli, but well those between positive VOT stimuli, she might have adopted a strategy consisting in giving "similar" responses to the negative VOT pairs and "different" responses to positive VOT pairs, perhaps to balance the total number of similar and different responses. If this is correct, the absence of a discrimination peak on the voicing continuum for this subject would not be due to a lack of categorical perception, but to the reduced audibility of fairly small $(20 \mathrm{~ms})$ VOT differences, especially those involving negative VOT. For the place of articulation continuum, this subject (CI 1) presents an observed discrimination peak similar to the one of the control group. This suggests that this subject is endowed with $\mathrm{CP}$, although the observed discrimination function is somewhat different from the expected one. However, the discrepancy between 
observed and expected discrimination scores is due to a somewhat erratic labeling function.

\subsubsection{Boundary Precision}

For one of the two CI children who successfully passed the minimal pair test, the /də-tə/ and /bə-də/ labeling functions are not very different from those of the control group, suggesting similar boundary precision. The other CI child with successful minimal pair discrimination had fairly inconsistent labeling functions, though boundary precision was inside the distribution of control values.

\subsubsection{Minimal pairs and Categorical Perception}

In this study, only the children who were successful in the minimal pairs test were given the categorical perception tests. The results suggest that children who can discriminate minimal pairs above some threshold $(75 \%$ correct discrimination here) have categorical perception, although this has to be confirmed with a larger sample. While one can reasonably suppose that failure to discriminate minimal pairs means lack of categorical perception, this should also be verified. It is indeed possible to be endowed with categorical discrimination even with low labeling performances.

\section{Conclusions}

This study provides some hints on the relationship between minimal pair discrimination, categorical perception and precision of the labeling boundary in both normal-hearing children and the deaf children with CI. The results of experiment 1 confirm the effect of age on boundary precision and show that age also contributes to improve categorical perception. The results of experiment 2 give the first insight on categorical perception in children with cochlear implants.

From these very preliminary results, it seems that CI children who can discriminate minimal phonological distinctions between syllables also possess categorical perception. This lends support to the idea of a functional link between speech intelligibility and categorical perception. However, this needs further confirmation with larger samples of CI children. 


\section{Acknowledgments}

We would like to thank Marie-Pierre Geron for her help and involvement in the experiment 1, and to Natalie Loundon, Denise Busquet and Nathalie Petroff for their participation in the experiment 2.

\section{References}

Burnham, D.K., Earnshaw, L.J. \& Clark, J.E. (1991). Development of categorical identification of native and non-native bilabial stops: infants, children and adults. Journal of Child Language, 18, 231-260.

Eimas, P.D., Siqueland, E.R., Jusczyk, P. \& Vigorito, J. (1971). Speech perception in infants. Science, 171, 303-306.

Hazan, V. \& Barrett, S. (2000). The development of phonemic categorization in children aged 6-12. Journal of Phonetics, 28, 377-396.

Liberman A.M., Harris, K.S. Hoffman, H.S. \& Griffith, B.C. (1957). The discrimination of speech sounds within and across phoneme boundaries. Journal of Experimental Psychology, 54, 358-368.

McCullagh, P. \& Nelder, J.A. (1983). Generalized Linear Models. London: Chapman \& Hall.

Medina V., Loundon, N., Busquet, D., Petroff, N. \& Serniclaes, W. (2004). Perception catégorielle des sons de parole chez des enfants avec Implant Cochléaire. JEP-TALNRECITAL. Fès, Maroc. 19-22 April 2004.

Miller, G.A. \& Nicely, P.E. (1955). An analysis of perceptual confusions among some English consonants. Journal of the Acoustical Society of America, 27, 338-352.

Miyamoto, R.T., Osberger, M.J., Todd, S.L., Robbins, A.M., Stroer, B.S. ZimmermanPhillips, S. \& Carney, A.E. (1995). Variables affecting implant performance in children. Laryngoscope, 104, 1120-1124.

Papçun, G. (1980). Discriminate analyses of four imitation dialects. UCLA WPP, Feb. 80, 48.

Pollack S. \& Pisoni, D. (1971) On the comparison between identification and discrimination tests in speech perception. Psychon.Science, 24, 299-300

Serniclaes, W. (submitted). "Allophonic perception in developmental dyslexia: origin, reliability and implications of the categorical perception deficit."

Serniclaes, W. (2000). La perception de la parole. In P. Escudier, G. Feng, P. Perrier, J.-L. Schwartz (eds.) La parole, des modèles cognitifs aux machines communicantes. Paris: Hermès, 159-190.

Serniclaes, W., Ligny, Ch., Schepers, F., Renglet, Th. \& Mansbach, A.-L. (2002).Evaluation du bénéfice thérapeutique de l'Implant Cochléaire à l'aide de mesures de production de la parole. In W. Serniclaes (Ed.) Méthodes d'évaluation des performances de l'Implant Cochléaire - Methods for the assessment of Cochlear Implant performances. Brussels: Etudes et Travaux N 5, ILVP -ULB, 31-48 
Vickers, D.A., Moore, B.C.J. \& Baer T. (2001). Effects of low-pass filtering on the intelligibility of speech in quite for people with and without dead regions at high frequencies. Journal of Acoustical Society of America, 110, 1164-1174.

Vieu, A., Mondain, M., Sillon, M., Piron, J. P. \& Uziel, A. (1999). Test d'Evaluation des Perceptions et Productions de la Parole (TEPPP). Revue de Laryngologie, Otologie et Rhinologie, 120, 219-225, 1999.

Vihman, M.V. (1996) Phonological development: The origins of language in the child. Cambridge (MA): Blackwell.

Werker, J.F. \& Tees, R.C. (1984). Cross-language speech perception: Evidence for perceptual reorganization during the first year of life. Infant Behaviour and Development, 7, 49-63.

Werker, J.F. \& Logan, J.S. (1985). Cross-language evidence for three factors in speech perception. Perception \& Psychophysics, 37, 35-44.

Werker, J.F. (2003). Baby steps to learning language. The Journal of Pediatrics, 143, 62-69.

Wood, C.C. (1976). Discriminability, response bias, and phoneme categories in discrimination of voice onset time. Journal of the Acoustical Society of America, 60, 1381-1389. 